\title{
Role of a medication in polyurethane foam in the treatment of diabetic foot lesions
}

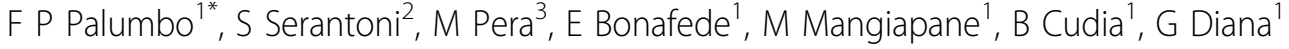 \\ From de Senectute: Age and Health Forum \\ Catanzaro, Italy. 5-7 December 2009
}

\section{Background}

The treatment of diabetic foot lesions need medications capable of managing wound infection and exudates that, variously combined, can influence the natural history of the pathology and therefore limb survival. A particular and economic device, is represented by honeycomb structure polyurethane foam Ligasano $\odot$.

\section{Material and methods}

We evaluated 5 patients with a diabetic foot and a case history of infected wounds until flemmone. The lesions have been debrided and/or surgically drained and then medicated three time a week, with variable thickness Ligasano $(0,5$ and $1 \mathrm{~cm})$. Tissue sample was collected to perform colture and antibiogram. According to diabetic foot guidelines of Consensus Conference 2003 patients ( 3 male and 2 female - mean age 54,3 years) were affected by skin lesions of the foot and were classified as in Table 1. Medications were performed until the reduction and/or complete healing.
Table 1

\begin{tabular}{ll}
\hline Complications & Number of patients \\
\hline glycometabolic failure & $4 / 5$ \\
cardiovascular complications & $3 / 5$ \\
kidney disease & $1 / 5$ \\
rethinic disease & $2 / 5$ \\
\hline
\end{tabular}

\section{Results}

The patients have been medicated once a day for 10 days $(2,5)$ and/or once every three weeks $(3 / 5)$ for the first two months. The mean time of the treatment was of 196 day for 4 patients. In 1 patient a minor cardiovascular event occurred and time of therapy was 296 days.

\section{Conclusions}

In our experience the device was proved to be economic and manageable, allowing the management of the exudates and avoiding, at the same time, the involvement of the perilesional skin that constitutes itself an innovation on the treatment of diabetic foot lesion.

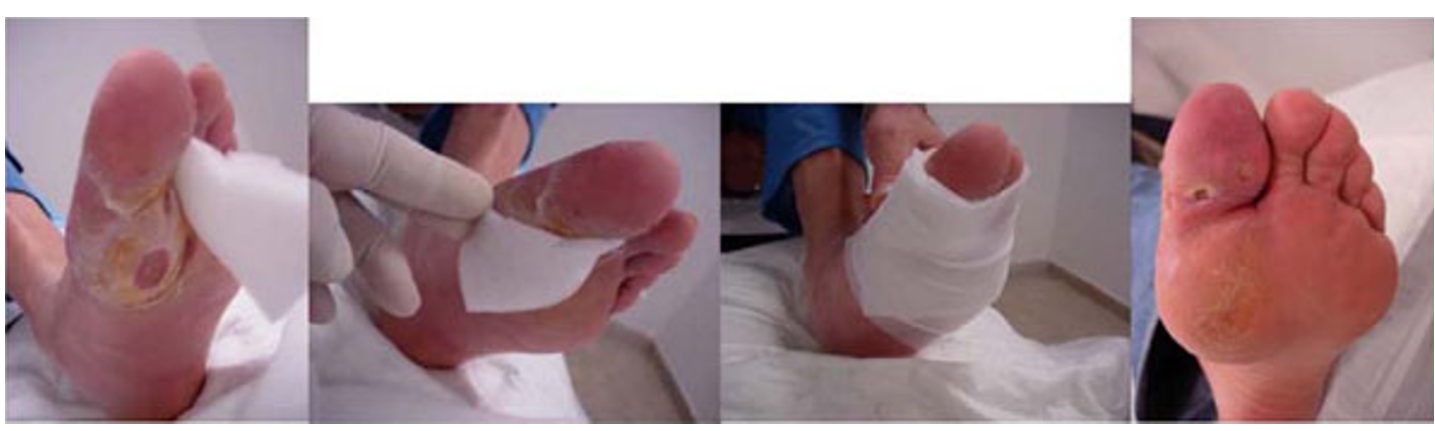

Figure 1 Plantar lesion.

"U.O. Chirurgia Geriatrica, A.O.U. Policlinico "Paolo Giaccone", Palermo, Italy 


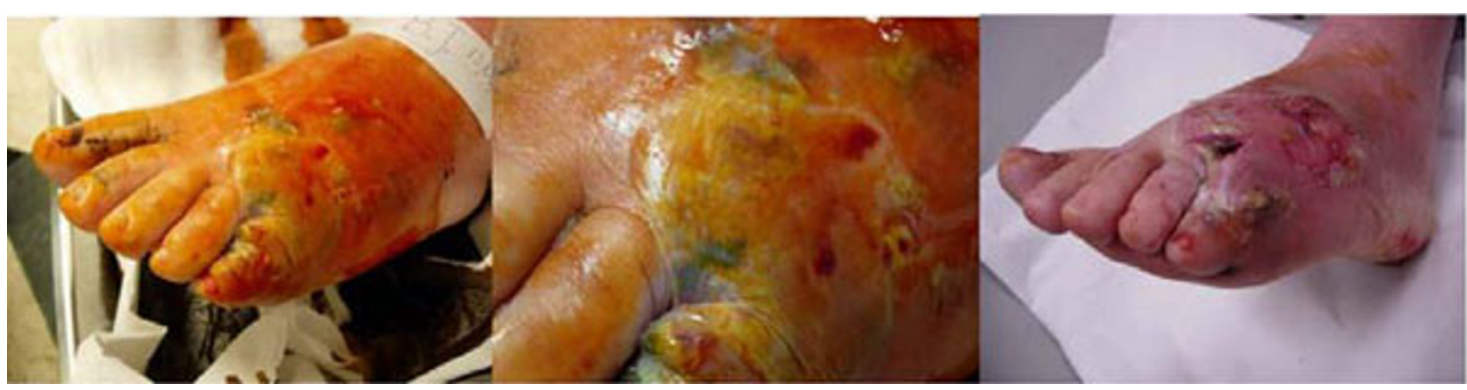

Figure $\mathbf{2}$ Infected lesion of the dorsum of the foot onset because the patient wears unqualified shoe.

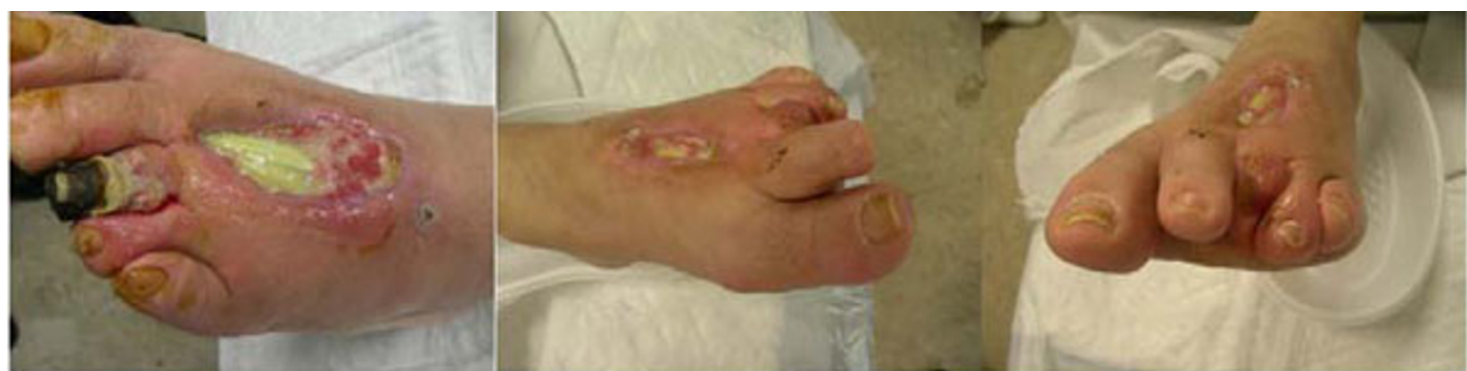

Figure 3 Infected lesion with tendons exposure.

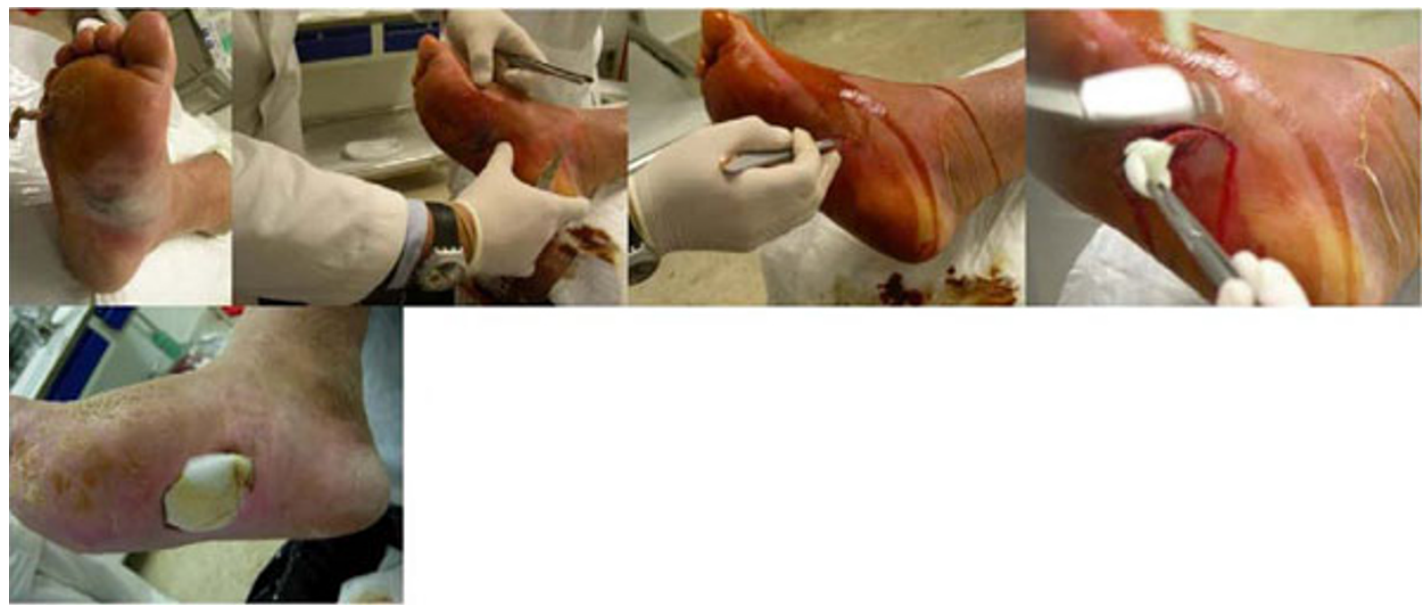

Figure 4 Flemmone of the left foot surgically drained and treated with antibiotic therapy and intracavitary Ligasano.

\section{Author details}

'U.O. Chirurgia Geriatrica, A.O.U. Policlinico "Paolo Giaccone", Palermo, Italy. ${ }^{2}$ Centro per la Diagnosi e la Terapia delle Ulcere Vascolari, Casa di Cura "Villa Fiorita", Prato, Italy. ${ }^{3}$ Centro per la Diagnosi e la Terapia delle Ulcere Vascolari, Casa di cura "San Camillo", Versilia Righi, Viareggio, Italy.

Published: 19 May 2010

\section{References}

1. Zoellner P, Kapp H, Smola H: A prospective, open-label study to assess the clinical performance of a foam dressing in the management of chronic wounds. Ostomy Wound manage 2006, 52(5):34-6.
2. Napoli B, Benigno A, D'Arpa N, Amico M, Conte F: Local treatment of burns with honeycomb expanded polyurethane (Ligasano). Annals of Burns and Fire Disaster 2008, XXI n.1.

3. Zemlin C: Studio sull'impiego di Ligasano come medicazione primaria nelle lesioni del piede di origine diabetica. Ligamed 2008.

doi:10.1186/1471-2318-10-S1-A71

Cite this article as: Palumbo et al:: Role of a medication in polyurethane foam in the treatment of diabetic foot lesions. BMC Geriatrics 2010

10(Suppl 1):A71. 